$\widehat{\mathcal{G}}_{\text {http://dx.doi.org/10.3765/sp.9.2 }}^{\text {Semantics \& Pragmatics Volume 9, Article 2: 1-28, } 2016}$

\title{
A novel problem for the likelihood-based semantics of even
}

\author{
Yael Greenberg \\ Bar-Ilan University
}

Submitted 2014-07-30 / First decision 2014-10-20 / Revision received 2014-12-08 / Second decision 2015-03-06 / Revision received 2015-04-14 / Accepted 2015-04-27 / Final version received 2016-06-08 / Published 2016-11-30

\begin{abstract}
This paper describes and examines novel data which is problematic for the popular view that the scale in the scalar presupposition of even is based on comparative (un)likelihood or probability. Several theories in the past attacked this characterization of the scale by pointing out examples where even is felicitous although the likelihood-based presupposition does not seem to be met, indicating that the comparative unlikelihood of $p$ is not a necessary condition for a felicitous use of even $p$. In contrast to these theories, this paper examines novel data where even is infelicitous although the likelihood-based presupposition is met, indicating that the comparative unlikelihood of $p$ is not a sufficient condition for a felicitous use of even $p$. In particular, I look at the unexpected infelicity of even $p$ in the context of a salient $p$ or $q$ alternative. I examine, and reject, several potential objections to the claim that such sentences pose a problem for the likelihood-based approach to even and conclude that the novel data constitute a real challenge for this popular approach to even.
\end{abstract}

Keywords: even, scales, presupposition, disjunction, likelihood, additivity, alternatives, focus

\section{Introduction}

The goal of this paper is to describe and examine novel data which is problematic for the widely held view that the scale in the scalar presupposition

* Thanks to the reviewers of Semantics and Pragmatics for constructive comments. Thanks also to Elitzur Bar-Asher Siegal, Luka Crnič, Roni Katzir, Barbara Partee, Galit Sassoon, Ivy Sichel, and especially Gennaro Chierchia, Danny Fox and Michael Wagner for helpful comments. All errors are, of course, mine. Research on this project was partially supported by ISF grant 490 / 2009 .

(C)2016 Yael Greenberg

This is an open-access article distributed under the terms of a Creative Commons Attribution License (http://creativecommons.org/licenses/by/3.o/). 
of even is based on (un)likelihood or probability. In particular, this presupposition is usually assumed to require that the prejacent of even is less likely than all its contextually supplied focus alternatives. This assumption underlies many of the current discussions of English even and other even-like operators cross linguistically, like the 'ambiguity' vs. 'scope' debate on even, the claims that (some) Negative Polarity Items involve an overt or a covert even-like operator, the discussion on the interactions between even and the covert exh(aust) operator, etc.

Several theories in the past attacked this characterization of the scale by pointing out examples where even is felicitous although the likelihood-based presupposition does not seem to be met; indicating that unlikelihood of the prejacent is not a necessary condition for a felicitous use of even. In contrast to these theories, this paper examines novel data where even is infelicitous although the likelihood-based presupposition is met, indicating that the unlikelihood of the prejacent is not a sufficient condition for a felicitous use of even.

To anticipate, notice that even is infelicitous in (1) although drinking tea seems to asymmetrically entail, and to be less likely than, drinking tea or coffee:

(1) John drank tea or coffee. Bill (\#even) drank $[\text { tea }]_{F} \cdot{ }^{1}$

The structure of this paper is as follows: in section 2 I give some background regarding the semantics of even and the debate about the type of scale in its presupposition. In section 3 I describe the novel argument against the likelihood-based view, concentrating on cases where even $p$ is infelicitous although $p$ is less likely than a salient $p$ or $q$ alternative (as in (1) above). In this section I also examine, and reject, several potential objections to this argument and describe other constructions illustrating the novel problem. I conclude that data as in (1) constitutes a real challenge for the likelihood-based semantics of even, and indicates that it requires serious reconsideration. Developing a solution for this challenge is beyond the scope of this paper, but at the end of this section I point out a potential direction which may be fruitful for doing so. Section 4 summarizes and points out some directions for future research.

1 This example was first pointed out in Greenberg 2014. 
A novel problem for the likelihood-based semantics of even

\section{Background: The semantics of even}

\subsection{The lexical entry for even}

Following much work on the semantics of even (see e.g., Horn 1969, Karttunen \& Peters 1979, Rooth 1985, 1992, Chierchia 2013) the lexical entry I adopt is in (2):

(2) $\llbracket$ even $\rrbracket^{g, c}=\lambda C \cdot \lambda p: \forall q \in C\left[q \neq p \rightarrow p>_{c} q\right] . \lambda w \cdot p(w)=1$ Where $C \subseteq \llbracket p \rrbracket^{F} \wedge \llbracket p \rrbracket^{O} \in C \wedge \exists q[q \neq p \wedge q \in C]$

Given (2), even is a sentential operator which combines with a set of propositions $C$, a proposition (namely its prejacent) $p$ and a world of evaluation $w$. It has one presupposition (the 'scalar presupposition') requiring $p$ to be stronger on a scale $\left(>_{c}\right)$ in the context of utterance than every proposition $q$ in $C$ distinct from $p$, and it asserts that $p$ is true in $w$. Following Rooth 1992, $C$ is a contextually supplied subset of the focus semantic value of $p$ (i.e., of the set of propositions identical to $p$ except for the focused element, which is substituted by an element of the same semantic type), containing $p$ and at least one other proposition.

The entry in (2) is not completely agreed upon. One debated component in it concerns the universal quantification in the presupposition, i.e., the requirement that $p$ is stronger than ALL alternatives in $C$. Theories like Kay 1990, Rullmann 1997, 2007 and Lahiri 2008 pointed out felicitous uses of even in sentences like (3)-(4), which they took to be problematic for this component:

(3) Not only did Mary win her first round match, she even made it to [the semifinals] $]_{\mathrm{F}}$ (Kay 1990: 89)

(4) (There were 10 problems in the quiz.) John solved 5 problems. Bill even solved [6 problems $]_{\mathrm{F}}$.

Clearly, making it to the semifinals (where potentially one can make it to the finals), or solving six problems out of ten are not the strongest potential alternatives. Some theories, then, proposed to replace the scalar presupposition in (2) by a weaker version requiring $p$ to be stronger than most alternatives, or from a salient alternative, for example, what Kay (1990) called 'the context proposition'.2 However, keeping the universal quantification in the lexical

2 Notice, though, that some theories proposed that strength of $p$ relative to a contextually salient alternative does not characterize even in English, but other even-like operators 
entry of even seems both possible and desirable. It is possible, since in (2) $p$ is not required to be stronger than all alternatives in $\llbracket p \rrbracket^{F}$, but rather in all alternatives in $C$, which is a contextually supplied subset of $\llbracket p \rrbracket^{F}$. Thus, for example, given the salient proposition preceding the sentences with even in (3) and (4), we can take $C$ in them to have only two members, as in (5)-(6) (where the prejacent is in italics): ${ }^{3}$

(5) $\quad$ Mary won the first round match, Mary made it to the semifinals\}

(6) $\quad$ Bill solved 5 problems, Bill solved 6 problems $\}$

Moreover, keeping the universal quantification component seems also desirable, as indicated by the examination of cases where more than one alternative is salient in the context:

(7) (Harry, John and Bill participated in the sports competition.) Harry made it to the finals, John won his first round match, and Bill (??even) made it to [the semifinals $]_{\mathrm{F}}$.

(8) (There were 10 problems in the quiz.) Harry solved 7 problems. John solved 5 problems. And Bill (??even) solved [6 problems $]_{\mathrm{F}} \cdot{ }^{4}$

If all that even presupposed was that $p$ is stronger than the context proposition, then (7)-(8) should be just as felicitous as (3)-(4) above. Instead, the reduced felicity of even in these sentences seems to be due to the fact

cross linguistically, for example incluso in Spanish (Lahiri 2008), bhii in Hindi (Schwenter \& Vasishth 2001), and bixlal in Hebrew (Greenberg 2014).

3 Notice that in (4), the salient sentence John solved 5 problems, i.e., the one before the sentence with even, affects the construction of alternatives in $C$ although it is not itself a member of $C$. In other words, the presence of this salient sentence, which is not a member of $C$, makes Bill solved 5 problems a member of $C$ in (6), though the latter proposition is not explicitly uttered.

This situation is legitimate given the assumption (see e.g., Rooth 1992) that the alternatives in $C$ should all be identical to $p$ except for the focused element (6 problems in (4)). An alternative direction, pointed out by a reviewer, is to integrate the contrastive topic status of the subjects in sentences like (4), and build a new set of alternatives in $C$ of the form $x$ solved $N$ problems. See also the brief discussion of this option in section 3.2 below, as well as M. Zimmermann 2014 about the association of even with contrastive topics. I will leave a deeper discussion of this option to further research.

4 These can be fine only if we accommodate a situation where, for example, Bill is particularly weak in sports or math, or usually doesn't win or solve anything. In such cases we ignore the preceding sentences and compare the prejacent to alternatives representing the expected behavior of Bill. 
A novel problem for the likelihood-based semantics of even

that although $p$ is indeed stronger than the alternative contributed by its preceding sentence, it is not stronger than all the contextually supplied alternatives. Thus, it seems that universal quantification over a contextually supplied subset of the focus alternatives should be indeed kept in the scalar presupposition of even.

Three other debated components in the lexical entry for even in (2) above concern the direction of ordering in the scalar presupposition, covered by the 'scope' vs. 'ambiguity' debate, the presence vs. absence of an additive presupposition (in addition to the 'scalar' presupposition) and the precise characterization of the scale in the scalar presupposition. In this paper I will remain neutral about the 'scope' vs. 'ambiguity' debate (see, e.g., Karttunen \& Peters 1979, Wilkinson 1996, Guerzoni 2003, vs. Rooth 1985, von Stechow 1991, Rullmann 1997, Giannakidou 2007 for discussions) and will discuss the assumed presence of the additive presupposition in section 3.2 below. The characterization of the scale in the scalar presupposition, to which I now turn, will be the main focus of this paper.

\subsection{The characterization of the scale for even: Previous debates}

The question I will focus on in this paper concerns the precise conditions which should be met for $p$ to be considered 'stronger on the scale' than $q$. More technically, how should we characterize the scale $>_{c}$ in (2) above?

The popular answer to this question, originated in Karttunen \& Peters 1979, Rooth 1992 and Lahiri 1998, is that the scale $>_{c}$ in (2) is based on (un)likelihood or probability, so even $p$ presupposes that $p$ is most unlikely among the alternatives in $C$. This is many times phrased as requiring $p$ to be the least likely alternative, so the lexical entry for even in (2) is often written as in (9):

(9) $\llbracket$ even $\rrbracket^{g, c}=\lambda C \cdot \lambda p: \forall q \in C\left[q \neq p \rightarrow p<_{\text {likely }} q.\right] \lambda w \cdot p(w)=1$

An immediate advantage of such a characterization is its ability to account for the felicity contrast in (10a) and (1ob):

(10) a. (John won a bronze medal in the competition) and Bill even won [silver $]_{\mathrm{F}}$.

b. (John won a gold medal in the competition) and Bill (\#even) won [silver $]_{\mathrm{F}}$.

Given the focus on 'silver' and the preceding sentences, the sets $C$ in (10a) and (10b) seem to be (11a) and (11b), respectively: 
(11) a. $\mathrm{C}=\{$ Bill won bronze, Bill won silver $\}$

b. $\mathrm{C}=\{$ Bill won gold, Bill won silver $\}$

Making natural assumptions about the likelihood of winning different medals, the contrast in (10) can be easily attributed to the fact that the likelihood-based presupposition is met in (10a) but fails in (1ob): while Bill won silver is less likely than Bill won bronze, it is not less likely (but in fact more likely) than Bill won gold.

In addition, the likelihood-based view of even has other well-known achievements. It was shown to account for the interaction of overt even with DE operators (e.g., Lahiri 1998) with modals, covert exh and non-monotone operators (e.g., Crnič 2012a,b, 2014), with questions (e.g., Guerzoni 2004), etc. It was also extended to account for the behavior of some Negative Polarity Items, by assuming that their semantic structure involves a covert variant of even (e.g., Lahiri 1998, Nakanishi 2006, Chierchia 2013).

Notice, though, that other theories in the past objected to this likelihoodbased characterization of the scale for even, based on cases where even seems perfectly felicitous although its prejacent does not seem less likely than its alternatives. Consider, for example, (12)-(17):

(12) A: It looks as if Mary is doing well at Consolidated Widget. George, the second vice president, likes her work.

B: That's nothing. Even $[\text { Bill }]_{F}$, the president, likes her work. (Kay 1990: 84)

(13) John is a political nonconformist. He even read [Manufacturing Consent $]_{\mathrm{F}}$ although it has been banned by the censorship committee. (Rullmann 1997: 55)

(14) Granny was accused of kidnapping, and even [murder $]_{\mathrm{F}}$. (Francescotti 1995: 165)

(15) (Seller to client:) Both tools are strong. The one on the right is made of strong aluminum, and the one of the left is even made of [steel $]_{\mathrm{F}}$. (Greenberg 2014: 3)

(16) Everyone is remarking on Mary's improvement. Last week she beat the number ten player, and this week, just as everyone expected, she even beat the number two player. (Kay 1990: 84)

(17) A: It's already 9.30. Should we start without John?

B: Well, he said he will be late by 15 minutes. But given the weather and 
A novel problem for the likelihood-based semantics of even

traffic today it is more likely that he will arrive even [later $]_{\mathrm{F}}$ (so let's indeed start without him).

Kay (1990) points out that (12) may be felicitous even if "nothing is assumed or inferred about the comparative likelihood of George and Bill liking Mary" (Kay 1990: 84). Similarly, Rullmann (1997) observes that in (13):

Manufacturing Consent need not be a particularly unlikely book for John to read. Because of his political views he may be even drawn to controversial or censored books. Rather, the relevant scale on which Manufacturing Consent occupies the topmost position could be one that ranks books according to the degree to which they reflect nonconformist thinking or their suitability for banning. (Rullmann 1997: 56)

Moreover, Francescotti (1995) observes that (14) is felicitous although it is not less likely, but in fact more likely for somebody to be accused of murder than of kidnapping. Similarly, even is perfectly felicitous in (15) although for a working tool being made of steel is not less likely, but perhaps more likely than being made of strong aluminum. Finally, in (16) and (17) it is explicitly claimed that $p$ is in fact expected (in (16)) or more likely (in (17)) than its alternative, but nonetheless even is felicitous.

Given such examples, various intuitive alternative characterizations of the scale for even have been proposed, such as 'weak informativity' (Kay 1990), 'noteworthiness' (Herburger 2000), 'unexpectedness relative to a contextually determined aspect' (Francescotti 1995) or 'correlation of the alternatives with a contextually supplied gradable property’ (Rullmann 2007). Historically, though, such suggestions were not seriously integrated into the research on even. This seems to have two independent reasons. The first is that it is not clear that data such as (12)-(17), which motivated such proposals, actually seriously puts the likelihood-based view at risk. For example, in (12) one may quite easily accommodate a situation where the fact that the president likes Mary's work is considered less likely than its alternative. In (13) one may take even to be felicitous because the criterion for determining unlikelihood should rest on what is normal for a regular person, and not for John.

Second, even if there are some felicitous uses of even which pose a real problem for the likelihood-based view (perhaps (15) is such a case), the alternative characterizations of the scale proposed in the past remained too intuitive and were not formally developed. It is not clear, for example, how 
to measure 'noteworthiness' or how alternatives 'correlate' with a graded property. In reality, then, most current theories of even and of NPIs (using a covert counterpart of even) continue to rely on the traditional likelihoodbased presupposition, ${ }^{5}$ and the comparative likelihood view of even remained predominant.

In the following section, though, I examine novel data which seems to indicate that the comparative likelihood view of even should be more seriously reconsidered.

\section{A novel problem for the likelihood-based characterization of the scale for even}

The data which has been used until now to object to the likelihood-based characterization of $>_{c}$ involved cases where even $p$ is felicitous in the context of an alternative $q$, although $p$ is not less likely than this alternative. Such cases were meant to lead to the conclusion in (18):

(18) Comparative unlikelihood of $p$ is not necessary for the felicity of even $p$.

In contrast to this type of data, the novel data I would like to examine now involves cases where even $p$ is infelicitous in the context of an alternative $q$, although $p$ is less likely than this alternative.

\subsection{The basic data: Infelicitous even $p$ in the context of a salient $p$ or $q$ alternative}

Consider again the sentence in (1), repeated here as (19), as well as in B's utterance in (20):

(19) John drank tea or coffee. Bill (\#even) drank [tea $]_{\mathrm{F}}$.

(20) A: Bill drank tea or coffee.

B: He (\#even) drank [tea $]_{F}$.

A prediction of the comparative unlikelihood view of even is that even $p$ will be felicitous when $p$ asymmetrically entails $q$, unless $p$ and $q$ are contextually equivalent and hence equiprobable. ${ }^{6}$ This is because the notion of

5 For example see Karttunen \& Peters 1979, Rooth 1992, Wilkinson 1996, Lahiri 1998, Guerzoni 2004, Nakanishi 2006, Crnič 2012b, 2014, Chierchia 2004, 2006, 2013.

6 Thanks to a reviewer for pointing out this constraint. 
A novel problem for the likelihood-based semantics of even

likelihood respects entailment: if $p$ asymmetrically entails $q$, then unless they are contextually equivalent, $p$ is also less likely than $q$, for it is true in fewer situations (see e.g., Lahiri 1998, Chierchia 2013, Crnič 2012b, 2014).

Now, in both (19) and (20) Drinking tea asymmetrically entails Drinking tea or coffee (under a generalized notion of entailment). This also holds for the prejacent Bill drank tea, which asymmetrically entails its focus alternative Bill drank tea or coffee (constructed based on the salient material before the sentence with even). Moreover, Bill drank tea seems also less likely than Bill drank tea or coffee, since there is no reason for why the former should be considered contextually equivalent to, and hence equi-probable to the latter. ${ }^{7}$

Crucially, then, if the scalar presupposition of even $p$ is based on likelihood, it should be met in (19) and (20), and even should be felicitous. In reality, however, this is not the case: even is infelicitous in these sentences. ${ }^{8}$

7 The problem with such sentences holds not only for the standard approach to the semantics of or as the inclusive disjunction operator of propositional logic $(\vee)$, which for simplicity I follow here, but also for other, less standard approaches. For example, $p$ still entails, and is less likely than $p$ or $q$ under Alonso-Ovalle's (2006)Alonso-Ovalle's (2008) approach to or, which takes it to introduce a set of alternatives into the representation which are bound by existential closure (in non-embedded sentences, as in (19)-(20)). In this case we end up with the same truth conditions as in the standard approach to or.

Another nonstandard approach to or takes it to express a list of epistemic possibilities with a closure operation (T. E. Zimmermann 2000, see also Geurts 2005). Under this approach, Bill drank tea or coffee entails that it is possible (given the speaker's knowledge in $w_{\mathrm{o}}$ ) that Bill drank tea and it is possible that Bill drank coffee. This approach was rejected (in, e.g., Sauerland 2004 and Alonso-Ovalle 2006, 2008) and it was instead argued that the epistemic possibilities inference is not truth conditional but is an 'ignorance implicature', which is a special case of a quantity implicature. Under both approaches, though, Bill drank tea is still less likely than the conjunction of epistemic possibilities entailed by Bill drank tea or coffee (under T. E. Zimmermann's approach), or implied by it (under the 'ignorance implicature' approach). This is because $p$, being known to speaker to hold in $w_{0}$, is still less likely than possibly $p$ and possibly $q$, even if it does not entail this alternative (unless one takes $q$ to be highly unlikely, which does not seem to be the case here). Thanks to Michael Wagner (p.c.) for pointing out the potential relevance of these approaches of or. See also section 3.5 below for more cases where epistemic possibility inferences may lead to the infelicity of even.

8 Notice that the infelicity of a similar sentence like (i) is rather easy to explain as a result of a clash with the ignorance implicature of the disjunction in the first sentence. In fact, they are infelicitous even without even. (Thanks to Luka Crnič (p.c.) for this observation.)

(i) Bill drank tea or coffee. \# He even drank [tea $]_{F}$.

This explanation, however, does not cover the infelicity of even in (19), in which the subjects of the salient sentence and the sentence with even refer to different individuals, or in (20), where the two sentences are uttered by different speakers. 
Yael Greenberg

This seems to lead to the conclusion in (21):

(21) Comparative unlikelihood of $p$ is not sufficient for the felicity of even p.9

One may wonder, though, whether the conclusion in (21) is indeed necessary. In particular, one may object to this conclusion by attempting to keep the likelihood-based presupposition and attribute the infelicity of even in (19)(20) to some independent factors. In the following subsections I examine, and reject, several such potential objections.

\subsection{Examining objection \#1 to the novel argument: Triviality due to an additive presupposition of even?}

The first potential objection I will consider has to do with the possibility of deriving the infelicity of even in (19)-(20) from its assumed additive presupposition.

\subsubsection{Other cases of infelicitous even with entailed alternatives}

To the best of my knowledge, the data noted in (19)-(20) is novel. The only similar data that I am aware of concerns the infelicity of even in cases where $p$ seems to entail its alternative, as in (22), observed in Wagner 2014:

(22) I was hoping that at least some of the students would be able to pass the test.

\#But in the end, even everyone was able to do it. (Wagner 2014: 3)

Similarly to (19)-(20), in (22) even is infelicitous although $p$ (Every student was able to pass the test) seems to asymmetrically entail its salient alternative

One could also try and account for the infelicity of even in (20) by arguing that A's utterance conveys that it is not settled whether Bill drank coffee or tea and that B's utterance is made with this assumption in mind. Suppose we assume that it is 50\% likely that he had tea and 50\% likely that he had coffee. Now B's utterance conveys (via a presupposition) that Bill drinking tea is less likely than his drinking coffee. But the proposition that he drank tea is asserted, and perhaps we cannot accept an assertion with such low degree of likelihood unless it is somehow hedged. Crucially, though, this kind of explanation cannot be extended to explain the infelicity of even in (19). Thanks to a reviewer for pointing out this direction.

9 This conclusion is strictly speaking trivial, since even $p$ can be also infelicitous when $p$ itself is infelicitous. I intend (21), then, to concern only the presupposition of even, assuming that $p$ itself is felicitous. Thanks to Luka Crnič (p.c.) for this point. 
A novel problem for the likelihood-based semantics of even

(some of the students were able to pass the test), and is less likely than it. Crucially, though, Wagner attributes this infelicity to the presence of an additive presupposition triggered by even.

Such an additive presupposition, formalized in (23), has indeed long been claimed to be triggered by even, alongside its 'scalar' presupposition, and is the source of the popular classification of even as a 'scalar additive' particle (see, e.g., Karttunen \& Peters 1979, Rooth 1985, 1992):

(23) An additive presupposition for even: $\exists q \in C[q \neq p \wedge q(w)=1]$.

As Wagner argues, if even in (22) indeed presupposes (23), then its infelicity can be naturally explained as a result of redundancy. More specifically, if even $p$ presupposes the truth of at least one alternative different from $p$ in C, and if one of the alternatives in $C$ is entailed by $p$, as in (22), then the additive presupposition is trivially met, since, given the truth of $p$ (asserted by even $p$ ), the entailed alternative in $C$ must be true as well. Wagner (2014) thus takes entailed alternatives to be generally banned with additive particles (cf. Krifka's (1999) discussion of stressed too, and Cohen's (2009) 'distinctness condition' on also in terms of event semantics).

Thus, one can suggest that in (19)-(20) too, the infelicity of even is due to the presence of an additive presupposition. More specifically, we can make the hypothesis in (24):

(24) Hypothesis: even $p$ in (19)-(20) is infelicitous because even triggers an additive presupposition which is trivially met in case an alternative in $C$ is entailed by $p$.

But if this hypothesis is correct, then the problem for the likelihood-based scalar presupposition noted above does not exist anymore, and the conclusion in (21) above is wrong.

\subsubsection{Previous debates about the presence of an additive presupposition with even}

What appears to strongly support the hypothesis in (24) is the observation that, as seen in (25)-(26), the classical additive particle, also, is blocked in the same environments as even in (19)-(20) above: ${ }^{10}$

(25) John drank tea or coffee. Bill (\#also) drank [tea $]_{F}$.

10 Thanks to a reviewer for pointing out this parallel. 
(26) A: Bill drank tea or coffee

B: He (\#also) drank [tea $]_{\mathrm{F}}$.

Notice, though, that whereas the presence of an additive presupposition is an undebated contribution of also and too, the presence of such a presupposition with even is disputed. In particular, various theories pointed to felicitous uses of even in sentences which do not, or cannot, give rise to any additive inference. Consider for example (27)-(28):

(27) A: Is Claire an [assistant $]_{F}$ professor?

B: No, she's even an [associate $]_{F}$ professor. (Rullmann 1997: 45)

(28) Hasiba even won the [gold medal] $]_{\mathrm{F}}$ (Lahiri 2008: 361)

In (27) and (28) the alternatives are mutually exclusive, and hence an additive inference is naturally blocked (Rullmann 1997, 2007, Lahiri 2008). Indeed, even is felicitous in (27) and (28) although these sentences do not imply that Claire has any other academic rank, or that Hasiba won any other medal in the competition, respectively. Rullmann (1997) more forcefully makes this argument by showing that unlike (27) with even, the minimally contrasting dialogue with also in (29), for which the additive component is clearly entailed, is infelicitous:

(29) A: Is Claire an [assistant $]_{\mathrm{F}}$ professor?

B: No, she's (\#also) an [associate $]_{\mathrm{F}}$ professor. (Rullmann 1997: 46)

Notice that the lack of the additive inference with even is also found in cases where the alternatives are compatible with each other, as in (30):

(30) a. (Seller to client): Both tools are strong. The one on the right is made of strong aluminum, and the one on the left is even made of [steel $]_{\mathrm{F}}$.

b. (Context: Bill and John read difficult books). Bill read book B. John even read [book A $]_{F}$.

These sentences can be felicitously uttered without implicating that the second tool is made of any other material besides steel, or that John read any other book besides book A.

Finally, the interaction of even with exclusive operators also poses problems for the additivity of even. Thus, von Stechow (1991) and Krifka (1991) point to the felicity of even in examples like (31a), where the inference that Bill danced with someone different from Sue would contradict the exclusivity inference triggered by only. This contrasts with the infelicity of (31b) with a combination of the also and only: 
A novel problem for the likelihood-based semantics of even

(31) a. Bill even danced only with [Sue $]_{F}$. (von Stechow 1991)

b. Bill (\#also) danced only with $[\text { Sue }]_{F}$.

Such data lead some theories (e.g., von Stechow 1991, Rullmann 1997) to suggest that, unlike also, the additive inference is not part of the semantics of even, but can be some sort of an implicature (derived from the interaction with its scalar presupposition, as suggested by Rullmann 1997), or that even presupposes that the other alternative is taken to be true in a counterfactually similar world (Lahiri 2008). More recently Wagner (2014) argued that the presence vs. absence of the additive presupposition may be systematically correlated with the syntactic position of even. In particular, he notes that the additive presupposition is present when even attaches to a DP (DP-even), but not to a VP (VP-even), as illustrated in (32): ${ }^{11}$

(32) The results in the Marathon were quite surprising. A Russian won the gold medal.

a. \#Even a Canadian won the silver medal. (unless two people won it)

b. \#The silver medal was won even by a Canadian. (unless two people won it)

c. The silver medal was even won by a Canadian. (one winner of silver medal) (Wagner 2014: 4)

Wagner (2014) thus predicts that unlike DP-even, which is infelicitous with entailed alternatives due to the triviality of the additive presupposition, VP-even, for which this presupposition is absent, will be fine with entailed alternatives. This prediction seems indeed to be borne out, as shown in Wagner's minimal pair in (33):

(33) Did John read some of the books?

a. \#John read even all of the books. (DP-even, additive ps. is trivially met, hence infelicity)

b. John even read all of the books. (VP-even, no additive ps. - no triviality, hence felicity)

Turning now back to the sentence in (19)-(20), notice that similarly to (33b) they involve VP-even. Remember that we hypothesized in (24) that

11 Notice, though, that given the felicity of even in sentences like (27) (where even appears before the DP an associate professor, without triggering an additive presupposition), the right characterization may relate not to DPs vs. VPs, but to referential vs. predicative expressions. 
the infelicity of even in (19)-(20) may be due to the fact that the additive presupposition triggered by it is trivially met with entailed alternatives, similarly to what happens with also in (25)-(26). But if even is indeed different from also in that it does not necessarily trigger an additive presupposition, as suggested in Rullmann 1997, Lahiri 2008, von Stechow 1991, and Krifka 1991 and, more specifically, if VP-even in these sentences indeed systematically lacks an additive presupposition, as suggested in Wagner 2014, then the infelicity of even in (19)-(20) cannot be attributed to such triviality, and the hypothesis in (24) is wrong. If this is the case then we are back to the problem for the likelihood-based scalar presupposition, summarized in the conclusion in (21).

\subsubsection{Can a weakened additive presupposition for even account for its infelicity in (19)-(20)?}

But perhaps there is still a way to save the hypothesis in (24), and attribute the infelicity of even in (19)-(20) to the presence of another, weakened version of the additive presupposition, and thus to indirectly save the likelihoodbased scalar presupposition. Such a way may rely on the observation ${ }^{12}$ that the core example in (19) involves a Contrastive Topic (CT) configuration, which does involve additivity qua Büring's (1997)Büring's (2003) partial answerhood condition for such structures. Crucially, CT-configurations require a context proposition of the form $x R y$, with $\mathrm{x}$ and $\mathrm{y}$ standing for CT and FOC-alternatives, respectively. Exactly the same holds for VP-even in the CT-configuration (32b) from Wagner 2014, which appears to presuppose the truth of a context proposition not of the form $x$ won the silver medal, but of the form $x$ won a $y$ medal, with non-trivial alternatives in the CT-position and in the FOC-position. The same holds for examples (30a) and (31b). The presence of such a 'weakened' additive presupposition is supported by the fact that (32b) cannot be used 'discourse-initially' (as seen in $(34)^{13}$, or if the context makes clear that nobody else won a medal (as in (35)):

(34) A: How was the marathon?

B: Good! \#A [Norwegian] $]_{\mathrm{CT}}$ even won the [gold] $]_{\mathrm{F}}$ medal.

12 Thanks to a reviewer for this observation, data and the consequent suggestion below.

13 The term 'discourse initially' was suggested by a reviewer. In (34) and in (36) below it can be taken to refer to a case where the sentence with even appears with no explicit alternative prior to it in the discourse. 
A novel problem for the likelihood-based semantics of even

(35) This year, nobody was awarded the gold medals in the shotout competition, as the winners were later disqualified for drug abuse. \#The silver medal was even won by [a Canadian $]_{\mathrm{F}}$.

Such data may be taken to show that VP-even does come with additivity presuppositions, albeit a weakened one, which is of a different kind than those observed with DP-even. If so, and given the striking parallel between the infelicity of even in (19)-(20) and also in (25)-(26), the infelicity of the former can be said to follow directly, and would therefore seem to have no bearing on the question of whether the scale for even should be characterized as likelihood-based or not. This will immediately reject the conclusion in (21) ("Comparative unlikelihood of $p$ is not sufficient for the felicity of even $p$ ").

However, while the interaction of even with Contrastive Topics and the effect of this interaction on the presence of some version or other of an additive presupposition are important to understand and require serious investigation in the future, I don't think such an investigation would have direct consequences for the conclusion in (21). This is mainly because the infelicity of even $p$ in the context of a salient disjunction is seen not only when even appears with a contrastive topic, as in (19), but also without it, as in (20) and crucially, when even appears without contrastive topic it does not systematically trigger any kind of additive presupposition, not even the 'weakened' one suggested above. This last point is supported by several facts: First, given informants' judgments, even is felicitous when appearing without CT in 'discourse initial' cases, as in (36), unlike what seen in (34):

(36) a. A: How was the marathon? B: Good! I even won the [gold] $]_{F}$ medal!

b. A: How was the exam? B: Great! I even got $[90]_{\mathrm{F}}$ !

Second, unlike what is seen in (35), when even appears without CT it is felicitous when the context forces an exclusive inference. For example even in (37a) is felicitous when the context makes it clear that nobody else won any other medal. Similarly, even is felicitous in (37b) although it is clear that neither Bill, nor any other individual got any other grade:

(37) a. A: How was the marathon?

B: It was great. I was the only one who got a medal, and it was even the $[\text { gold }]_{\mathrm{F}}$ medal.

A: Really? How's that?

B: Well, the people who were supposed to get the bronze and silver medals were later disqualified for drug abuse, so nobody won these medals. 
b. A: How did you and Bill do in the exam?

B: Well, eventually Bill didn't take it, so I was the only one there. But it was wonderful. I was expecting to get a good grade, but I thought of maximally 85 , and eventually I got even better than that: 90 !

Furthermore, despite the striking similarity between even in (19)-(20) and also (in (25)-(26)), the two particles are different with respect to the possibility to appear with entailed alternatives: In particular, unlike also, for which entailed alternatives are indeed completely banned, sentences with even are many times perfectly felicitous with entailed alternatives. This can be seen already in Wagner's (2014) example (33b) above. Moreover, when asked to compare the use of even and also in this sentence, as seen in (38a), as well as in the minimal pairs in (38b)-(38e) below, informants were very clear about the felicity of the former and the oddness of the latter, although in both cases $p$ appears in the context of salient entailed alternative: ${ }^{14}$

(38) a. A: Did John read some of the books?

B: He even / \#also read [all $]_{\mathrm{F}}$ of the books. (cf. Wagner's example (33))

b. A: We need a signature of a professor on this form B: Well, John is a professor. He is even / \#also a [full $]_{\mathrm{F}}$ professor.

c. A: How was the exam? Did you pass?

B. Yes. I even / \#also [got 9o $]_{F}$.

d. A: Did you get a medal in the competition?

B: Sure. I even / \#also got the [gold $]_{F}$ medal.

e. The queen gave birth to a child. She even / \#also gave birth to [a boy $]_{\mathrm{F}} !^{15}$

14 One may argue that the salient alternatives in (38a) and (38c) are obligatorily exhaustified (meaning "John read some but not all of the books" and "John got a pass grade and not more than that", respectively), and hence are not entailed by the prejacent of even. Such a claim, though, does not seem to hold for the rest of the cases in (38) (e.g., the salient alternative in (38e) does not seem to be interpreted as "The queen gave birth to a child but not to a boy" (cf. Fox's (2007) 'innocent exclusion' constraint)).

15 Some of the sentences in (38) with also can be felicitous if $p$ and its alternatives are understood to involve two different entities (e.g., if I won two medals, or if the queen gave birth to two children, respectively, cf. Wagner's examples in (32a)). Crucially, no such inference is necessary with the minimally contrasting versions with even. 
A novel problem for the likelihood-based semantics of even

\subsubsection{Taking stock: Additivity is still an open issue for even, but it cannot explain its infelicity in (19)-(20)}

The above discussion points to two main conclusions: The first is that the additivity of even is not fully understood yet. In particular, the conditions under which even triggers an additive presupposition, and the exact nature of this presupposition in different syntactic and contextual environments (e.g., when even is attached to DPs vs. VPs, with vs. without Contrastive Topics) clearly require further research.

The second conclusion relates more specifically to the main claim of this paper and to the conclusion in (21) above. In particular, we have seen that the attempt to attribute the infelicity of (19) and (20) to the interaction between the existence of an additive presupposition of some sort triggered by even and the general ban against entailed alternatives with additive particles, does not seem to work. As seen above this is both because even does not systematically trigger an additive inference (not even a 'weakened' one), and because, unlike also, it is sometimes perfectly fine with entailed alternatives. Thus, although indeed both also $p$ and even $p$ are bad with a salient disjunction alternative (of the form $p \vee q$ ), as seen again in the comparison of (19)-(20) and (25)-(26), we cannot use this similarity to reduce the reasons for infelicity of the former to the reasons for the infelicity of the latter, and to refute conclusion (21).

Eventually, understanding the exact reasons for the infelicity of even in (19)-(20), as opposed to its felicity with the entailed alternatives in (38), is, of course, highly desirable (see Greenberg 2015 for a suggestion). At this point, though, my goal is much more modest, namely to argue that the reason is not simply the presence of an additive presupposition, and therefore, that such data pose a problem for the likelihood-based view of even.

\subsection{Examining objection \#2 to the novel argument: A too complex alter- native in $C$ ?}

In deriving the conclusion in (21), we took the contextually supplied set of focus alternatives in (19)-(20) to be $C_{1}$ as in (39):

(39) $C_{1}$ \{Bill drank tea or coffee, Bill drank tea $\}$

However, if $C_{1}$ is indeed the operative set of alternatives for (19)-(20), then one may try to attribute the infelicity of even in it to the fact that the only alternative distinct from $p$ in this set is more complex than it, and 
hence not an appropriate alternative to start with. Such a claim can rely on arguments concerning the 'symmetry problem' regarding alternatives in scalar implicatures (e.g., von Fintel \& Heim 1997, Horn 2000, Fox \& Katzir 2011, Katzir 2014). For example, in order to derive the right scalar implicature to John read some of the books, namely that John did not read all of the books, it is necessary to assume that the alternative to this sentence is (40a), but not (4ob), although both are stronger than this sentence (both seem to asymmetrically entail it):

(40) Potential alternatives to John read some of the books:

a. John read all of the books.

b. John read some but not all of the books.

If (4ob) is allowed as an alternative to John read some of the books, we wrongly predict that John read some of the books can have (40a) as its scalar implicature. Fox \& Katzir (2011) and Katzir (2014) have noted that the same problem is found with alternatives to focused constituents, and, following ideas in Grice 1991, McCawley 1978, and Horn 1984, suggested that in alternative sensitive constructions, the alternatives which can substitute an element $\mathrm{X}$ must be syntactically at most as complex as it.

Based on these observations, one may assume that Bill drank tea or coffee is an illegitimate alternative to Bill drank tea, since it is more complex than it, and hence should not be in $C_{1}$. If no other alternative is in this set, then perhaps the infelicity of even in (19)-(20) is due to the fact that the only alternative in the set of alternatives is inappropriate, so no comparative unlikelihood can be calculated.

There are, however, two problems with such a claim. First, based on examples brought by Matsumoto (1995), it has been already argued (e.g., Fox \& Katzir 2011, Katzir 2014) that alternatives built from salient material are allowed in $C$ even if they are more complex than $p .{ }^{16}$ Second, the problem

16 In particular, Katzir's characterization of the allowable substitutions of focus propositions is as in (i)-(ii). The possibility of using complex alternatives if they are constructed using contextually salient material is guaranteed by clause (iic):

i. $X^{\prime}$ is an allowable substitution for $X$ in a context $C$ if $X^{\prime}$ can be derived from $X$ by successive steps in which a subconstituent $\mathrm{z}$ of $\mathrm{X}$ is replaced with an element of the substitution source for $\mathrm{z}$ in C, SS $(z, C)$.

ii. SS $(\mathrm{z}, \mathrm{C})$, the substitution source for $\mathrm{z}$ in context $\mathrm{C}$, is the union of:

a. The lexicon 
A novel problem for the likelihood-based semantics of even

for the likelihood-based presupposition noted above exists not only with disjunctions as in (19)-(20), where the contextually salient alternative can be said to be more complex than $p$, but also with existentially interpreted indefinites, where the alternative to $p$ is as complex as it. Consider, for example, (41a), where $C$ can be assumed to be (41b):

(41) a. The red box has fruits. The blue one (??even) has [apples] $]_{F}$ in it.

b. \{the blue box has fruits, the blue box has apples\}

Here too even is odd, though for some informants its status improves on two conditions: First, if the speaker knows that the red box has no apples and second, if she assumes that having apples (relative to having other types of fruits) is noteworthy (though not necessarily unlikely or less likely). For example, a seller can tell (41) to me knowing that the red box has no apples but the blue one does, and that I am mostly interested in apples now (e.g., I am planning to prepare an apple pie), even if having apples is in fact a likely kind of fruit to have. Crucially, however, such constraints on the felicity of even in (41a) are again unexpected given the likelihood-based presupposition and $C$ as in (41b): Having apples asymmetrically entails and is less likely than having fruits (when it is not contextually equivalent to it), even if having apples is not noteworthy in any way.

\subsection{Examining objection $\# 3$ to the novel argument: Failure of the like- lihood-based presupposition due to a different construction of $C$ ? $^{17}$}

A third attempt to explain the infelicity of even in (19)-(20) is to assume that the contextually supplied set of focus alternatives to $p$ in these sentences is not $C_{1}$ in (39), repeated in (42) (with its schematic representation in the brackets), but another set. Given current discussions about the alternatives triggered by disjunctions (e.g., Sauerland 2004, Alonso-Ovalle 2006, 2008), three main possibilities which come to mind are $C_{2}, C_{3}$ and $C_{4}$ in (43)-(45) (and their schematic representations in the brackets):

(42) $C_{1}$ \{Bill drank coffee or tea, Bill drank tea $\} .(\{p \vee q, p\})$

b. The sub-constituents of $\mathrm{z}$

c. The set of salient constituents in C (that is, constituents of the structures of utterances made in recent discourse (Katzir 2014: 10).

17 Thanks to Danny Fox (p.c.) for pointing out this direction. 
(43) $C_{2}$ \{Bill drank coffee, Bill drank tea\}. $(\{q, p\})$

(44) $C_{3}$ \{Bill drank coffee or tea, Bill drank coffee, Bill drank tea\}. $(\{p \vee q, q, p\})$

(45) $C_{4}$ \{Bill drank coffee or tea, Bill drank coffee and tea, Bill drank coffee, Bill drank tea $\}.(\{p \vee q, p \wedge q, q, p\})$

Unlike $C_{1}$, if any of these sets is constructed as the actual $C$ that even in (19)-(20) operates on, the infelicity of even in these sentences can be explained using the likelihood-based presupposition: In $C_{2}$, we can argue that $p$ (Bill drank tea) is not less likely than $q$ (Bill drank coffee). In $C_{3}$ and $C_{4} p$ is less likely than the disjunction $p \vee q$, but is not necessarily less likely than all the alternatives in $C$ : In $C_{3}$ this is because we can again argue that $p$ is not less likely than $q$, and in $C_{4}$ it is clearly not less likely than the conjunction $p \wedge$ $q$. Using any of these possible sets, then, the likelihood-based view seems to correctly predict that even is infelicitous in (19)-(20). This would make conclusion (21) wrong.

But, similarly to the attempts in sections 3.2 and 3.3 , these attempts can be rejected as well. Consider first the data in (46)-(48):

(46) Mary hit John. Sue even [stabbed him $]_{F}$.

(47) Mary stabbed John. Sue (\#even) [hit him $]_{\mathrm{F}}$.

(48) Mary hit or stabbed John. Sue (\#even) [stabbed him] $]_{F}$.

The felicity contrast between (46) and (47) can be easily accounted for if we adopt a likelihood-based scale for even, take $C$ in both cases to be the set in (49), and make the reasonable assumption that stabbing someone is less likely than hitting him or her. Given these assumptions even is felicitous in (46) but not in (47) since Sue stabbed John is less likely than its alternative in C, Sue hit John, but not vice versa.

(49) \{Sue hit John, Sue stabbed John \}

But now look at the infelicity of even in (48): Keeping the assumption that stabbing is less likely than hitting, and that the presupposition is based on likelihood, this infelicity is unexplained, no matter whether $C$ is constructed as $C_{1}, C_{2}$ or $C_{3}$ in (50) (which parallel the sets in (42), (43) and (44) above). In all of these cases Sue stabbed John comes out less likely than all its alternatives, so the presupposition is met and even in (48) is wrongly predicted to be felicitous: 
A novel problem for the likelihood-based semantics of even

(50) $C_{1}$ \{Sue hit or stabbed John, Sue stabbed John\}

$C_{2}$ \{Sue hit John, Sue stabbed John\}

$C_{3}$ \{Sue hit or stabbed John, Sue hit John, Sue stabbed John\}

As for $C_{4}$ in (45), a problem in trying to attribute the infelicity of even in (19)-(20) to the presence of the conjunction in this set is that that we get the same kind of infelicity also in cases like (51), where adding a conjunction to $C$ (i.e., Bill is a full professor and an associate professor) is not reasonable, due to mutual incompatibility of the properties in the disjuncts:

(51) John is a full professor or an associate professor. Bill is (\#even) a full professor.

To summarize, then, no matter how $C$ is formed, it seems that a likelihoodbased semantics for even cannot capture the full range of facts concerning even $p$ in the context of salient disjunctions.

\subsection{Other constructions illustrating the novel problem, and a potential direction for further research}

Until now, we concentrated on cases where even $p$ is infelicitous in the context of a salient explicit disjunction, as in (19)-(20). But the explicit disjunction case is not isolated. I would like to end this paper by describing other constructions which pose a similar problem for the likelihood-based view. One such construction, already mentioned above is (41a) repeated here as (52), involves existentially closed indefinites. Other such constructions involve the superlative modifiers at most and at least as in (53a) and (53b), and a possibility modal as in (53c). Even is infelicitous in all of them: ${ }^{18}$

(52) The blue box has fruits. The red one (??even) has [apples] (infelicitous if apples are not noteworthy in any respect)

(53) a. John drank at most five beers. Bill (\#even) drank [five beers] $]_{F}$.

b. John drank at least five beers. Bill (\#even) drank [five beers] $]_{F}$.

c. It's possible that John drank the worst possible coffee. Bill (\#even) $[\text { did }]_{\mathrm{F}}$ drink the worst possible coffee.

18 Thanks to Michael Wagner (p.c.) for pointing out the data in (53), and for the idea, described below, that it is epistemic possibility which these constructions share with or in (19)-(20), and which might be incompatible with the scale for even. 
As noted above, having apples is less likely than having fruit, no matter whether the former is noteworthy in any case. Similarly, in (53a) and (53b) drank five beers seems to asymmetrically entail and be less likely than both drank at most five beers and drank at least five beers. Finally, in (53) it should be more likely for something to be possible than to be definitely true. In all of these cases, then, assuming the likelihood-based presupposition seems to wrongly predict even to be felicitous.

A direction for further research, then, is to try and isolate the common semantic component shared by all constructions in (19)-(20) and (52)-(53) and use it for a better characterization of the scale for even. For example, one may hypothesize that what all infelicitous uses of even reviewed above have in common is that their salient alternatives occur in constructions which give rise to inferences of epistemic possibilities. Indeed, some theories took sentences with or, as in (19)-(20) to express a list of epistemic possibilities (T. E. Zimmermann 2000, see also Geurts 2005). Under this approach, Bill drank tea or coffee entails that it is possible (given the speaker's knowledge in $w_{\mathrm{o}}$ ) that Bill drank tea and it is possible that Bill drank coffee. The epistemic possibility component is also present in some of the analyses of superlative modifiers as in (53a) and (53b) (e.g., Geurts \& Nouwen 2007, Nouwen 2010), and is of course at the heart of the possibility modal it is possible in (53c) (e.g., Kratzer 1981, 1989).

However, a proper development of the idea that the semantics of even is incompatible with epistemic possibilities, the exact understanding the reasons for this incompatibility, and the empirical verification of this idea require serious investigation which I have to leave to further research.

\section{Conclusion}

In this paper I examined cases where even $p$ is infelicitous when the alternative to $p$ in $C$ is asymmetrically entailed by, and is more likely than it. It is interesting to note in this respect the similarity of this phenomenon to other cases in which entailed or entailing alternatives are blocked, for example, the constraint on entailing alternatives with exclusives (observed in Schwarzschild 1997) ${ }^{19}$ and on entailed alternatives with additives (Krifka 1999, Wagner 2014). In the latter cases, however, the constraints on such alternatives can be derived from independent principles: For example, entailing

19 See von Fintel \& Heim (1997) who also observes the blocking of entailed alternatives with exclusives, which can be easily attributed to the need to avoid a contradiction. 
A novel problem for the likelihood-based semantics of even

alternatives have been claimed to be blocked with overt or covert exclusive operators (e.g., Exh(aust)) due to the need to prevent arbitrary contradictions, using the innocent exclusion constraint (Fox 2007, Chierchia, Fox \& Spector 2011), and entailed alternatives can be blocked with additive operators due to the need to avoid trivialities or redundancies (Krifka 1999, Wagner 2014, cf. the discussion in section 3.2). In contrast, the presence of an entailed alternative in the examples with infelicitous even examined in section 3 does not seem to be constrained by any of these mechanisms, as it does not lead to any potential contradiction or triviality.

The data above, then, seems indeed to show that the unlikelihood of $p$ relative to its alternatives in $C$ is not a sufficient condition for the felicity of even $p$, as suggested in conclusion (21) above. This seems like a real challenge to the likelihood-based characterization of the scalar presupposition for even, and indicates that it requires a serious reconsideration.

Notice that in this respect the intuitive alternative characterizations of the scalar presuppositions of even mentioned in section 2.2 (based on e.g., 'informativeness' or 'noteworthiness') do not fare any better than the comparative likelihood view. It is not clear, for example, why we cannot consider Bill drank tea as more noteworthy, or more informative than Bill drank tea or coffee, and given the imprecise nature of these suggestions, it is not clear how one can proceed in understanding the infelicity of such examples using these suggestions. The comparative likelihood view of even can at least make precise predications here (albeit ones which do not seem to be borne out in reality).

An important direction for further research, then, is to try and develop a precise characterization of the scale for even, which will be able to account for the full range of data considered above (see Greenberg 2015 for a suggestion). A wider potential implication concerns the covert counterpart of even. This covert operator is argued by some theories to be present in the semantic structure of sentences with certain NPIs (see e.g., Lahiri 1998, Chierchia 2004, 2006, 2013, but see Heim 1984 and Crnič 2014 for some objections). Such theories rely on properties of the likelihood-based scale assumed to exist with overt even, for example the fact that this scale is reversed under Downward-Entailing operators. But if the scale operative with overt even is not necessarily based on likelihood, as this paper suggests, the parallel between overt and covert even should be reconsidered as well. 
Yael Greenberg

\section{References}

Alonso-Ovalle, Luis. 2006. Disjunction in alternative semantics. University of Massachusetts, Amherst dissertation.

Alonso-Ovalle, Luis. 2008. Innocent exclusion in an alternative semantics. Natural Language Semantics 16(2). 115-128. http://dx.doi.org/10.1007/ s11050-008-9027-1.

Büring, Daniel. 1997. The meaning of topic and focus: The 59th Street Bridge accent (Routledge Studies in German Linguistics). London, New York: Routledge.

Büring, Daniel. 2003. On D-trees, beans, and B-accents. Linguistics and Philosophy 26(5). 511-545. http://dx.doi.org/10.1023/A:1025887707652.

Chierchia, Gennaro. 2004. Scalar implicatures, polarity phenomena, and the syntax/pragmatics interface. In Adriana Belletti (ed.), Structures and beyond: The cartography of syntactic structures, 39-103. Oxford University Press. http://dx.doi.org/10.1162/ling.2006.37.4.535.

Chierchia, Gennaro. 2006. Broaden your views: Implicatures of domain widening and the "logicality" of language. Linguistic Inquiry 37(4). 535-590. http: //dx.doi.org/10.1162/ling.2006.37.4.535.

Chierchia, Gennaro. 2013. Logic in grammar: Polarity, free choice, and intervention. Oxford University Press.

Chierchia, Gennaro, Danny Fox \& Benjamin Spector. 2011. The grammatical view of scalar implicatures and the relationship between semantics and pragmatics. In Claudia Maienborn Paul Portner \& Klaus von Heusinger (eds.), Handbook of semantics, vol. 3, 2297-2331. Berlin: Mouton de Gruyter. http://semanticsarchive.net/Archive/WMzY2ZmY/CFS_EmbeddedSIs. pdf.

Cohen, Shai. 2009. On the semantics of too and only: Distinctness and subsumption. University of Massachusetts, Amherst dissertation.

Crnič, Luka. 2012a. Focus particles and embedded exhaustification. Journal of Semantics 30(4). 533-558. http://dx.doi.org/10.1093/jos/ffso18.

Crnič, Luka. 2012b. On the meaning and distribution of concessive scalar particles. In Nicholas LaCara, Yelena Fainleib \& Yangsook Park (eds.), North Eastern Linguistics Society (NELS) 41, 143-156.

Crnič, Luka. 2014. Against a dogma on NPI licensing. In Luka Crnič \& Uli Sauerland (eds.), The art and craft of semantics: A Festschrift for Irene Heim, vol. 1, 117-145. MIT Working Papers in Linguistics (MITWPL) 70. http://semanticsarchive.net/Archive/jZiNmM4N/Crnic.pdf. 
A novel problem for the likelihood-based semantics of even

von Fintel, Kai \& Irene Heim. 1997. Class notes on pragmatics.

Fox, Danny. 2007. Free choice and the theory of scalar implicatures. In Uli Sauerland \& Penka Stateva (eds.), Presupposition and implicature in compositional semantics, 71-120. Basingstoke: Palgrave-Macmillan.

Fox, Danny \& Roni Katzir. 2011. On the characterization of alternatives. Natural Language Semantics 19(1). 87-107. http://dx.doi.org/10.1057/ 9780230210752_4.

Francescotti, Robert M. 1995. Even: The conventional implicature approach reconsidered. Linguistics and Philosophy 18(2). 153-173. http://dx.doi.org/ $10.1007 /$ BFoog85215.

Geurts, Bart. 2005. Entertaining alternatives: Disjunctions as modals. Natural Language Semantics 13(4). 383-410. http://dx.doi.org/10.1007/s11050005-2052-4.

Geurts, Bart \& Rick Nouwen. 2007. At least et al.: The semantics of scalar modifiers. Language 83(3). 533-559. http://dx.doi.org/10.1353/lan.2007. 0115 .

Giannakidou, Anastasia. 2007. The landscape of even. Natural Language and Linguistic Theory 25(1). 39-81. http://dx.doi.org/10.1007/s11049-0o69006-5.

Greenberg, Yael. 2014. External and internal alternative sensitive operators. Unpublished paper presented at a workshop on "Focus Sensitive Expressions from a Cross-Linguistic Perspective”, Bar Ilan University.

Greenberg, Yael. 2015. Even, comparative likelihood and gradability. In T. Brochhagen, F. Roelofsen \& N. Theiler (eds.), Amsterdam colloquium 2O, 147-156. http: / / semanticsarchive . net/Archive / mVkOTk2N / AC2015proceedings.pdf.

Grice, H. Paul. 1991. Studies in the way of words. Cambridge, MA: Harvard University Press.

Guerzoni, Elena. 2003. Why even ask? On the pragmatics of questions and the semantics of answers. Massachusetts Institute of Technology dissertation. http://hdl.handle.net/1721.1/17646.

Guerzoni, Elena. 2004. Even-NPIs in yes/no questions. Natural Language Semantics 12(4). 319-343. http://dx.doi.org/10.1007/s11050-004-8739-o.

Heim, Irene. 1984. A note on negative polarity and downward entailingness. In Charles Jones \& Peter Sells (eds.), North Eastern Linguistics Society (NELS) 14, 98-107.

Herburger, Elena. 2000. What counts: Focus and quantification. Cambridge, MA: MIT Press. 
Horn, Laurence. 1969. A presuppositional analysis of only and even. In Robert I. Binnick (ed.), Chicago Linguistics Society (CLS) 5, 98-107.

Horn, Laurence. 1984. Toward a new taxonomy for pragmatic inference: Qbased and R-based implicatures. In Deborah Schiffrin (ed.), Meaning, form, and use in context, 11-42. Washington, DC: Georgetown University Press. http://hdl.handle.net/10822/555477.

Horn, Laurence. 200o. From if to iff: Conditional perfection as pragmatic strengthening. Journal of Pragmatics 32(3). 289-326. http://dx.doi.org/10. 1016/So378-2166(99)0oo53-3.

Karttunen, Lauri \& Stanley Peters. 1979. Conventional implicature. In David A. Dinneen \& Choone Kyu (eds.), Syntax and semantics 11: Presupposition, 1-56. New York: Academic Press.

Katzir, Roni. 2014. On the roles of markedness and contradiction in the use of alternatives. In Semantics, pragmatics, and the case of scalar implicatures, 40-71. Palgrave. http://dx.doi.org/10.1057/9781137333285_3.

Kay, Paul. 1990. Even. Linguistics and Philosophy 13(1). 59-111. http://dx.doi. org/10.1007/BFoo630517.

Kratzer, Angelika. 1981. The notional category of modality. In Hans-Jürgen Elkmeyer \& Hannes Rieser (eds.), Words, worlds, and contexts, 38-74. Republished in Kratzer, Angelika. 2012. Modals and Conditionals: New and Revised Perspectives. Oxford University Press. Berlin \& New York: De Gruyter.

Kratzer, Angelika. 1989. An investigation of the lumps of thought. Linguistics and Philosophy 12. 607-653. http://dx.doi.org/10.1007/BFoo627775.

Krifka, Manfred. 1991. A compositional semantics for multiple focus constructions. In Semantics and Linguistic Theory (SALT) 1, 127-158. Ithaca, NY: Cornell University. http://dx.doi.org/10.3765/salt.viio.2492.

Krifka, Manfred. 1999. Additive particles under stress. In Devon Strolovitch \& Aaron Lawson (eds.), Semantics and Linguistic Theory (SALT) 8, 111-128. Ithaca, NY: CLC Publications. http://dx.doi.org/10.3765/salt.v8io.2799.

Lahiri, Utpal. 1998. Focus and negative polarity in Hindi. Natural Language Semantics 6. 57-123. http://dx.doi.org/10.1023/A:1008211808250.

Lahiri, Utpal. 2008. The semantics and pragmatics of some scalar expressions in Spanish. In Anuario del seminario de filología Vasca "Julio de Urquijo", vol. 42, 359-389.

Matsumoto, Yo. 1995. The conversational condition on Horn scales. Linguistics and Philosophy 18(1). 21-6o. http://dx.doi.org/10.1007/BFoo984960. 
A novel problem for the likelihood-based semantics of even

McCawley, James D. 1978. Conversational implicatures and the lexicon. In Peter Cole (ed.), Syntax and semantics 9: Pragmatics, 245-259. New York: Academic Press.

Nakanishi, Kimiko. 2006. Even, only, and negative polarity in Japanese. In Semantics and Linguistic Theory (SALT) 16, 138-155. Ithaca, NY: CLC Publications. http://dx.doi.org/10.3765/salt.v16io.2953.

Nouwen, Rick. 2010. Two kinds of modified numerals. Semantics and Pragmatics 3(3). 1-41. http://dx.doi.org/10.3765/sp.3.3.

Rooth, Mats. 1985. Association with focus. University of Massachusetts, Amherst dissertation. http://hdl.handle.net/1813/28568.

Rooth, Mats. 1992. A theory of focus interpretation. Natural Language Semantics 1(1). 75-116. http://dx.doi.org/10.1007/BFo2342617.

Rullmann, Hotze. 1997. Even, polarity, and scope. In Martha Gibson, Grace Wiebe \& Gary Libben (eds.), Experimental and theoretical linguistics, vol. 4, 40-64. Edmonton, Canada: Department of Linguistics, University of Alberta. http://semanticsarchive.net/Archive/WZhOWY5N/rullmannı997. pdf.

Rullmann, Hotze. 2007. What does even even mean? Unpublished manuscript, University of British Columbia.

Sauerland, Uli. 2004. Scalar implicatures in complex sentences. Linguistics and Philosophy 27(3). 367-391. http://dx.doi.org/10.1023/B:LING.0000023378. 71748.db.

Schwarzschild, Roger. 1997. Why some foci must associate. Unpublished manuscript, Rutgers University.

Schwenter, Scott \& Shravan Vasishth. 2001. Absolute and relative scalar particles in Spanish and Hindi. Berkeley Linguistics Society (BLS) 26. 225233. http://dx.doi.org/10.3765/bls.v26i1.1124.

von Stechow, Arnim. 1991. Current issues in the theory of focus. In Arnim von Stechow \& Dieter Wunderlich (eds.), Semantics: an international handbook of contemporary research. Berlin: Walter de Gruyter.

Wagner, Michael. 2014. Even and the syntax of focus sensitivity. Paper presented at a workshop on "Focus Sensitive Expressions from a CrossLinguistic Perspective”, Bar Ilan University.

Wilkinson, Karina. 1996. The scope of even. Natural Language Semantics 4. 193-215. http://dx.doi.org/10.1007/BFoo372819.

Zimmermann, Malte. 2014. Conventional vs free association with focus: Insights from West African and South East Asian languages. Paper presented 
at a workshop on "Focus Sensitive Expressions from a Cross-Linguistic Perspective”, Bar Ilan University.

Zimmermann, Thomas Ede. 2000. Free choice disjunction and epistemic possibility. Natural Language Semantics 8(4). 255-290. http://dx.doi.org/ 10.1023/A:1011255819284.

Yael Greenberg

Department of English Literature and Linguistics

Bar-Ilan University

Bldg. 404 room 211

Ramat-Gan, 5290002 Israel

yaelgree@gmail.com 